\title{
Low Prevalence of Leptospira Carriage in Rodents in Leptospirosis-Endemic Northeastern Thailand
}

\author{
Panadda Krairojananan ${ }^{1, *}$, Janjira Thaipadungpanit ${ }^{2,3}$, Surachai Leepitakrat ${ }^{1}$, \\ Taweesak Monkanna ${ }^{1}$, Elizabeth W. Wanja ${ }^{4}$, Anthony L. Schuster ${ }^{5}$, Federico Costa ${ }^{6,7}$, \\ B. Katherine Poole-Smith ${ }^{1}$ and Patrick W. McCardle ${ }^{1}$ (D)
}

1 Department of Entomology, Armed Forces Research Institute of Medical Sciences (AFRIMS), Bangkok 10400, Thailand; SurachaiL.fsn@afrims.org (S.L.); TaweesakM.fsn@afrims.org (T.M.); Betty.Poolesmith.mil@afrims.org (B.K.P.-S.); Patrick.McCardle.mil@afrims.org (P.W.M.)

2 Department of Clinical Tropical Medicine, Faculty of Tropical Medicine, Mahidol University, Bangkok 10400, Thailand; janjira.tha@mahidol.ac.th

3 Mahidol-Oxford Tropical Medicine Research Unit, Faculty of Tropical Medicine, Mahidol University, Bangkok 10400, Thailand

4 Department of Preventive Medicine and Biostatistics, Uniformed Services University of the Health Sciences, 4301 Jones Bridge Road, Bethesda, MD 20814, USA; Elizabeth.wanja@usuhs.edu

5 MEDCOM Headquarters, Fort Sam Houston, San Antonio, TX 78234, USA; anthony.l.schuster.civ@mail.mil

6 The Institute of Collective Health (ISC), Federal University of Bahia (UFBA), Rua Basílio da Gama, 316, Canela, Salvador CEP 40110-040, Brazil; frederico.costa@yale.edu

7 Department of Epidemiology of Microbial Diseases, Yale School of Public Health, 60 College St, New Haven, CT 06510, USA

* Correspondence: PanaddaK.fsn@afrims.org; Tel.: +66-662-696-2700 (ext. 4741)

Received: 27 August 2020; Accepted: 28 September 2020; Published: 30 September 2020 updates

\begin{abstract}
Leptospirosis is a neglected zoonotic disease affecting mostly the world's tropical regions. The rural people of northeastern Thailand suffer from a large number of leptospirosis infections, and their abundant rice fields are optimal rodent habitats. To evaluate the contribution of diversity and carriage rate of pathogenic Leptospira in rodent reservoirs to leptospirosis incidence, we surveyed rodents, between 2011 and 2012, in four provinces in northeastern Thailand with the highest incidence rates of human leptospirosis cases. We used lipL32 real-time PCR to detect pathogenic Leptospira in rodent kidneys, partial 16S rRNA gene sequencing to classify the infecting Leptospira species, and whole $16 \mathrm{~S}$ rDNA sequencing to classify species of isolated Leptospira. Overall prevalence of Leptospira infection was 3.6\% (18/495). Among infected rodents, Bandicota indica (14.3\%), Rattus exulans $(3.6 \%)$, and $R$. rattus $(3.2 \%)$ had renal carriage. We identified two pathogenic Leptospira species: L. interrogans $(n=15)$ and L. borgpetersenii $(n=3)$. In addition, an L. wolffii (LS0914U) isolate was recovered from the urine of $B$. indica. Leptospira infection was more prevalent in low density rodent populations, such as B. indica. In contrast, there was a lower prevalence of Leptospira infection in high density rodent populations of $R$. exulans and $R$. rattus.
\end{abstract}

Keywords: carriage; Leptospira; L. wolffii; rodent; Bandicota indica; 16S rRNA gene; Thailand

\section{Introduction}

Pathogenic Leptospira species are the causative agents of leptospirosis, one of the most common zoonotic diseases in the world [1]. Although rodents are the primary reservoir hosts for Leptospira, a variety of domestic and wild animals, such as dogs, buffaloes, cattle, pigs, and mongooses also serve as reservoirs and may transmit the disease to other animals through direct and indirect exposure to infected urine [2,3]. Infected animals shed Leptospira from their renal tubules into the environment via 
urine $[4,5]$. Most human leptospirosis cases are the result of contact with water or soil contaminated with the urine of infected animals [1].

In Thailand, leptospirosis is a reportable disease under the passive surveillance system of the Bureau of Epidemiology, Department of Disease Control, Ministry of Public Health (MoPH). The vast majority of human cases in northeastern Thailand occur during the rainy season (July to October). Agricultural workers, primarily rice farmers, are at higher risk, due to traditional practices of barefoot rice farming [6]. Rodent populations in rice fields have been reported as a potential sources of Leptospira. In previous studies, the seroprevalence rates of Leptospira in rodents trapped during 1998 to 2000 in epidemic areas from 10 provinces (Burirum, Udon Thani, Nakhon Ratchasima, Phetchabun, Phitsanulok, Chanthaburi, Chon Buri, Phra Nakhon Si Ayutthaya, Trang, and Surat Thani) across Thailand was approximately $4.8 \%$, with most seropositive rodents being found in northeastern rodent populations $(7.1 \%)$ [7].

The prevalence of Leptospirosis is underestimated. One reason for the underreporting of leptospirosis cases is that its nonspecific symptoms make it difficult to distinguish from other tropical diseases such as dengue, scrub typhus, and malaria [8,9]. Exacerbating this problem, Thailand lacks a system linking laboratory results back into the $\mathrm{MoPH}$ surveillance system, so leptospirosis surveillance is based on presumptive cases rather than laboratory confirmed cases [10]. Between 2006-2018, most leptospirosis cases (65-83\%) in the northeastern region of Thailand reported to the Thai $\mathrm{MoPH}$ were in populations working in agriculture-related jobs. While 47 to $64 \%$ of leptospirosis cases reported nationally in Thailand's MoPH passive surveillance system were attributed to occupational exposure among farmers [11], epidemiological studies showed that peridomestic environments contribute significantly to the leptospirosis burden in Thailand [7,12]. Moreover, little is known about which Leptospira strains normally circulate in northeastern Thailand. This lack of knowledge makes it difficult to attribute human disease to leptospirosis prevalence in specific rodent species. Understanding this relationship is critical in deciphering disease epidemiology and may be useful for leptospirosis prevention.

Previously, our preliminary survey data suggested a pattern of low prevalence of Leptospira in rodents related with a high incidence of human leptospirosis (unpublished data). In this study, we evaluated Leptospira prevalence in rodents, between 2011 and 2012, from four provinces in the northeastern region of Thailand with the highest incidence rates of human leptospirosis cases: Burirum, Kalasin, Sisaket, and Surin.

\section{Materials and Methods}

\subsection{Trapping Rodents}

Rodents were trapped in the Buriram, Kalasin, Sisaket, and Surin provinces in the northeastern region of Thailand (Figure 1). Rodent trapping was carried out only in areas that had reported human leptospirosis cases. Clusters of two or three villages were sampled during each trapping session. Each session lasted three consecutive nights and used 100 small wire live traps per night. In areas where reported cases were close together, three villages were sampled, while only two villages were sampled in areas where villages were far apart. In each trapping site, traps were randomly distributed and placed $5 \mathrm{~m}$ apart. To avoid heat stress for the rodents, trap placement was completed before 6 p.m. in the evening and animals were collected before 7 a.m. the following morning. Individual traps were baited with bananas or dried fish and then placed in different habitats in relation to human activity, including with houses (in the garden), flood plains, dry lands, and forested areas. To determine the relative abundance of the trapped rodents, trap success (TS) was calculated as described by Nelson and Clark [13]: TS $(\%)=(\mathrm{Tc} / \mathrm{Tn}) \times 100$, where $\mathrm{TS}=$ trapping success, $\mathrm{Tc}=$ the number of rodents trapped and $\mathrm{Tn}=$ the number of trap nights. The trap nights were calculated by multiplying the number of fully functional traps by the number of trap nights. Each morning trap was inspected and the number of trapped rodents counted. 


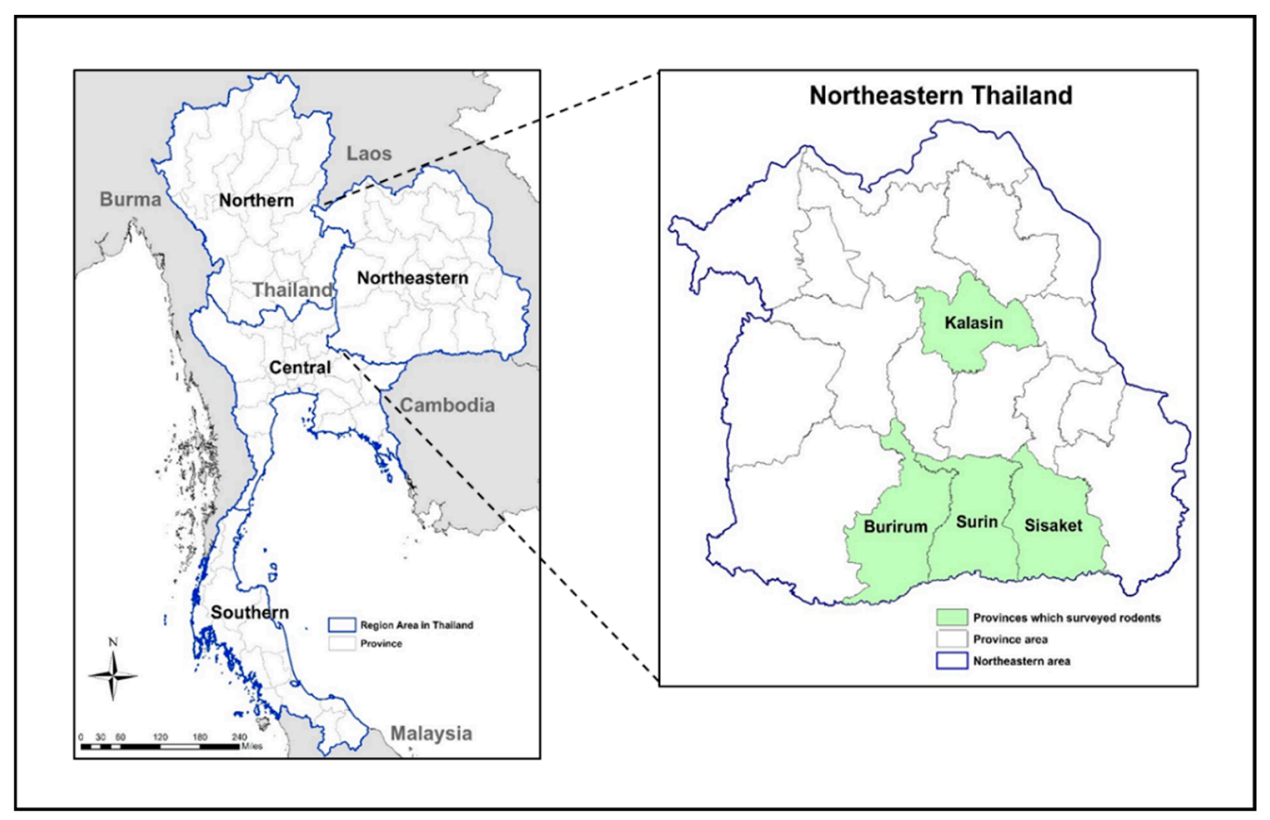

Figure 1. Map of Thailand showing the provincial locations for pathogenic Leptospira surveillance in rodent populations between 2011 and 2012. Four provinces (Burirum, Kalasin, Sisaket, and Surin) located in the northeast region of Thailand.

\subsection{Rodent Identification and Processing}

Trapped rodents were euthanized with carbon dioxide and identified at a species level. Species identification was based on external morphological guidelines by Lekagul and McNeely [14]. Necropsy was performed and tissues were collected. Direct puncture of a full urinary bladder was performed under aseptic conditions for urine collection (when available, 13 urine samples/495 rodents) for culture. One kidney from each rodent was removed to culture and isolate Leptospira. All procedures involving animals were in accordance with animal use protocols approved by the Institutional Animal Care and Use Committee (IACUC) of the Armed Forces Research Institute of Medical Science (AFRIMS), Bangkok, Thailand (Protocol Number 12-06, Field Sampling of Small Mammal; Orders: Erinaceomorpha; Soricomorpha; Scandentia; Macroscelidea and Rodentia; Populations to Support Zoonotic Diseases Surveillance and Ectoparasite Collection).

\subsection{Leptospira Cultures}

At the field site, all culturing was performed using 5-fluorouracil-containing EllinghausenMcCullough-Johnson-Harris (EMJH) medium (Difco, Franklin Lakes, NJ, USA) with 5\% rabbit serum. Each urine sample was dropped in $3 \mathrm{~mL}$ of $0.1 \%$ semisolid EMJH medium. A section of the cortex from one kidney of each animal was homogenized by forcing tissue through a disposable $3 \mathrm{~mL}$ syringe attached to 18-G hypodermic needle. Homogenates were suspended in $5 \mathrm{~mL}$ culture EMJH medium and tissue debris was allowed to precipitate. After $24 \mathrm{~h}, 500 \mu \mathrm{L}$ of the culture was subcultured into $3 \mathrm{~mL}$ semisolid EMJH medium and stored at room temperature until being transported back to AFRIMS. At the AFRIMS laboratory, the EMJH culture vials were incubated for 16 weeks at $30^{\circ} \mathrm{C}$ with biweekly dark field microscopic observation to verify the presence of Leptospira.

\subsection{Leptospira Carriage and Molecular Identification in Trapped Rodents}

Genomic DNA was extracted from kidney specimens using Wizard ${ }^{\circledR}$ Genomic DNA Purification Kit (Promega, Madison, WI, USA) according to the manufacturer's instructions. The presence of Leptospira DNA was screened using the lipL32 real-time assay that was modified from McAvin et al. [15] to suit the Chromo4 ${ }^{\mathrm{TM}}$ System (Bio-Rad, Hercules, CA, USA) as follows: $25 \mu \mathrm{L}$ of reaction mixtures were combined with $1 \times$ RealMasterMix Probe $(0.04$ units $/ \mu$ L HotMaster Taq DNA Polymerase, $2 \mathrm{mM}$ 
Magnesium Acetate, $0.4 \mathrm{mM}$ dNTPs with dUTP) (5 PRIME, Gaithersburg, MD, USA) according to manufacturer's instructions, with $0.1 \mu \mathrm{M}$ probe LPS-TM and $0.2 \mu \mathrm{M}$ each of primers LPS-F and LPS-R. Positive and negative control samples were included in each round of testing. The positive controls included DNA prepared from reference L. interrogans culture and from Leptospira-infected rodent kidney tissues collected during previous surveillance studies. DNA prepared from nonpathogenic L. biflexa culture and from noninfected rodent tissue were used as negative controls in the assay. Real-time PCR was performed under the following conditions: $95^{\circ} \mathrm{C}$ for $1 \mathrm{~min}, 45$ cycles at $95^{\circ} \mathrm{C}$ for $15 \mathrm{~s}, 60^{\circ} \mathrm{C}$ for $30 \mathrm{~s}$. Test samples giving cycle-to-threshold $(\mathrm{Ct})$ values lower than 40 were analyzed as positive. A nested single tube PCR assay [16] targeting partial 16S rDNA was performed on positive lipL32 real-time assay samples. Amplicons were visualized using 1.5\% gel electrophoresis followed by staining with GelStar (Lonza, Basel, Switzerland). Positive PCR samples were purified by GeneJET ${ }^{\mathrm{TM}}$ PCR Purification Kit (Fermentas, Waltham, MA, USA). After purification, samples were sent to the Macrogen laboratory (Macrogen Inc., Seoul, Korea) for Sanger sequencing. Molecular identification of Leptospira species by DNA sequencing of partial 16S rDNA amplicon from each DNA extracted from rodent's kidney samples was aligned using Sequencher ${ }^{\mathrm{TM}} \mathrm{v} 5.0$ software (Gene Codes Corporation, Miami, FL, USA), and trimmed to the 443 base-pairs region. Maximum likelihood trees were reconstructed from partial 16S rDNA sequence using an algorithm implemented in MEGA $X$ version 10.0.5 [17]. The model of sequence evolution used was the generalized time-reversible (GTR) model with gamma-distributed rate variation. The model parameters were adjusted as follows: transition/transversion ratio was fixed to 4.0, and the gamma shape parameter accounting for rate variation among sites and the proportion of invariant sites was optimized. We set the program to search the tree using the Nearest Neighbor Interchange (NNI) method and chose BioNJ as an initial tree. Interactive Tree of Life (iTOL) v4 [18] was used to display and edit the tree.

\section{5. $16 \mathrm{~S}$ rRNA Gene Amplification and Sequencing Analysis of Recovered Leptospira Isolate}

The isolated Leptospira was grown in liquid EMJH and incubated at $30^{\circ} \mathrm{C}$ for 7 days. Total genomic DNA was extracted from the culture using the GeneJET ${ }^{\mathrm{TM}}$ Genomic DNA Purification kit according to manufacturer's instructions (Fermentas, Waltham, MA, USA). PCR was performed using the 16S rRNA primer $\mathrm{fD} 1 / \mathrm{rD} 1$ [19]. After the first round of amplification, PCR products were diluted to $1: 10^{3}$, followed by a second round of amplification using the nested primers lepto16S11f/lepto16S1338r [20]. A reaction volume of $50 \mu \mathrm{L}$ was performed using 1 unit of KOD-Plus DNA polymerase (TOYOBO, Japan) with final primer concentration of $300 \mathrm{nM}$. Amplification was performed using a Veriti ${ }^{\mathrm{TM}}$ Thermal Cycle (Applied Biosystems, Waltham, MA, USA) with the following protocol: 2 min at $94{ }^{\circ} \mathrm{C} ; 35$ cycles $92{ }^{\circ} \mathrm{C}$ for $15 \mathrm{~s}, 63{ }^{\circ} \mathrm{C}$ for $30 \mathrm{~s}, 68^{\circ} \mathrm{C}$ for $2 \mathrm{~min}$, then a final extension of $68^{\circ} \mathrm{C}$ for $5 \mathrm{~min}$. PCR products were purified from $1 \%$ agarose gels in Tris-acetate-EDTA buffer using Quantum Prep ${ }^{\mathrm{TM}}$ Freeze' $\mathrm{N}$ Squeeze DNA Gel Extraction Spin Columns (Bio-Rad, Hercules, CA, USA) according to manufacturer's instructions. Purified PCR products were sequenced using primers lepto16S11f/lepto16S505f and lepto16S1006f as previously described [20]. Alignment of DNA sequence of the whole 16S rRNA gene and phylogenetic analysis was conducted as described above.

\subsection{Statistical Analysis}

The statistical analysis in this study performed with IBM SPSS Statistics 26.0 (IBM SPSS Statistics for Windows, Version 26.0., IBM Corporation, Armonk, NY, USA). A $p$-value of less than 0.05 was considered statistically significant. Fisher's exact test was used to compare the association between Leptospira prevalence and trapped rodent species and Leptospira interrogans prevalence among the Leptospira-positive rodents. Fisher's exact test with Spearman's rho correlation was done to determine whether correlation existed between human incidence and general Leptospira rodent prevalence. 


\section{Results}

A total of 495 rodents were trapped from the four provinces reporting the highest incidence of human leptospirosis cases to the MoPH since 2007 (Figure 1). Ten rodent species were trapped and identified (Table 1) based on taxonomic features. Overall trap success was $17.4 \%$. Among trapped rodents, $R$. exulans and $R$. rattus were the most frequently trapped species $(87.5 \%)$; these species were found in all four provinces. Of the total trapped rodents, $320(64 \%)$ were trapped from Burirum, $84(17 \%)$ from Sisaket, $48(10 \%)$ from Kalasin, and $43(9 \%)$ from Surin.

Table 1. Number of trapped rodents, PCR positive for Leptospira by study area and rodent species relative to the average annual incidence of human cases per 100,000 people reported to the $\mathrm{MoPH}$ in 2011 and 2012.

\begin{tabular}{|c|c|c|c|c|c|c|}
\hline & \multirow{2}{*}{$\begin{array}{l}\text { Average Annual Incidence } \\
\text { of Human Cases Per 100,000 }\end{array}$} & \multirow{2}{*}{$\begin{array}{l}\text { Number of Trapped } \\
\text { Rodents }(\%)\end{array}$} & \multirow{2}{*}{$\begin{array}{l}\text { Percentage of } \\
\text { Trap Success }\end{array}$} & \multicolumn{3}{|c|}{ Leptospira Prevalence (\%) } \\
\hline & & & & All & Linte $^{1}$ & Lborg $^{1}$ \\
\hline \multicolumn{7}{|l|}{ Provinces } \\
\hline Burirum & 23.54 & $320(64.6)$ & 15.72 & $11(3.4)$ & $8(2.5)$ & $3(0.9)$ \\
\hline Surin & 29.63 & $43(8.7)$ & 15.47 & $1(2.3)$ & $1(2.3)$ & 0 \\
\hline Sisaket & 26.97 & $84(17.0)$ & 32.85 & $6(7.1)$ & $6(7.1)$ & 0 \\
\hline Kalasin & 19.28 & $48(9.7)$ & 17.44 & 0 & 0 & 0 \\
\hline \multicolumn{7}{|l|}{ Rodent Species } \\
\hline Rattus exulans & & $246(49.7)$ & 8.27 & $9(3.6)$ & $6(2.4)$ & $3(1.2)$ \\
\hline Rattus rattus & & $187(37.8)$ & 6.22 & $6(3.2)$ & $6(3.2)$ & 0 \\
\hline Bandicota indica & & $21(4.2)$ & 0.68 & $3(14.3)$ & $3(14.3)$ & 0 \\
\hline Mus cervicolor & & $14(2.8)$ & 0.45 & 0 & 0 & 0 \\
\hline Mus caroli & & $13(2.6)$ & 0.42 & 0 & 0 & 0 \\
\hline Rattus losea & & $5(1.0)$ & 0.16 & 0 & 0 & 0 \\
\hline Rattus argentiventer & & $4(0.8)$ & 0.13 & 0 & 0 & 0 \\
\hline Bandicota savilei & & $3(0.6)$ & 0.1 & 0 & 0 & 0 \\
\hline Menetes berdmorei & & $1(0.2)$ & 0.03 & 0 & 0 & 0 \\
\hline Suncus murinus & & $1(0.2)$ & 0.03 & 0 & 0 & 0 \\
\hline Total & & $495(100)$ & 17.4 & $18(3.6)$ & $15(3.0)$ & $3(0.6)$ \\
\hline
\end{tabular}

The overall percentage of pathogenic Leptospira infection in kidneys detected by the lipL32 real time assay was $3.6(18 / 495)$. Leptospira prevalence in rodents from each province was determined; the highest infection rates was found in Sisaket (7.1\%), followed by Burirum $(3.4 \%)$ and Surin $(2.3 \%)$ (Table 1). No rodents from Kalasin were positive for Leptospira infection. We observed a positive but not statistically significant correlation between human incidence and general Leptospira rodent prevalence $(\mathrm{r}=0.4, p=0.6)$.

By the PCR-based investigation of kidney samples, three species (B. indica at $14.3 \%$, R. exulans at $3.6 \%$, and $R$. rattus at $3.2 \%$, as shown in Tables 1 and 2) were identified as Leptospira carriers. General Leptospira prevalence was higher in B. indica when compared to $R$. rattus $(p=0.05)$. Leptospira interrogans prevalence was also higher in B. indica when compared to $R$. exulans $(p=0.03)$ and $R$. rattus $(p=0.05)$. The lipL32 PCR assay positivity indicated pathogenic Leptospira carriage in rodents. Using the partial 16S rRNA gene sequence analysis and the maximum likelihood phylogenetic tree construction, two pathogenic Leptospira species were assigned for these samples: L. interrogans (83\%) and L. borgpetersenii (17\%) (Figure 2). The 443- nucleotide sequences of partial 16S rDNA sequences were submitted to GenBank with the accession numbers KP120894-KP120903 and KP120905-KP120912. L. interrogans or L. borgpetersenii harboring rodents were trapped in Burirum province. L. interrogans was found in rodents trapped from Sisaket and Surin (Table 1). L. borgpetersenii was only present in R. exulans, while L. interrogans was found in B. indica, R. exulans, and R. rattus. 
Table 2. Prevalence of Leptospira carriage in kidneys stratified by rodent species and provinces.

\begin{tabular}{ccccc}
\hline Rodent Species & Provinces & & & \\
\hline & Burirum & Surin & Sisaket & Kalasin \\
\hline Rattus exulans & $9 / 199(4.5 \%)$ & $0 / 23$ & $0 / 11$ & $0 / 13$ \\
Rattus rattus & $1 / 77(1.3 \%)$ & $1 / 11(9.0 \%)$ & $4 / 64(6.3 \%)$ & $0 / 35$ \\
Bandicota indica & $1 / 11(9.0 \%)$ & $0 / 6$ & $2 / 4(50.0 \%)$ & $0 / 0$ \\
Mus cervicolor & $0 / 14$ & $0 / 0$ & $0 / 0$ & $0 / 0$ \\
Mus caroli & $0 / 12$ & $0 / 0$ & $0 / 1$ & $0 / 0$ \\
Rattus losea & $0 / 4$ & $0 / 0$ & $0 / 1$ & $0 / 0$ \\
Rattus argentiventer & $0 / 1$ & $0 / 0$ & $0 / 3$ & $0 / 0$ \\
Bandicota savilei & $0 / 0$ & $0 / 3$ & $0 / 0$ & $0 / 0$ \\
Menetes berdmorei & $0 / 1$ & $0 / 0$ & $0 / 0$ & $0 / 0$ \\
Suncus murinus & $0 / 1$ & $0 / 0$ & $0 / 0$ & $0 / 0$ \\
Total & $11 / 320(3.4 \%)$ & $1 / 43(2.3 \%)$ & $6 / 84(7.1 \%)$ & $0 / 48(0 \%)$ \\
\hline
\end{tabular}

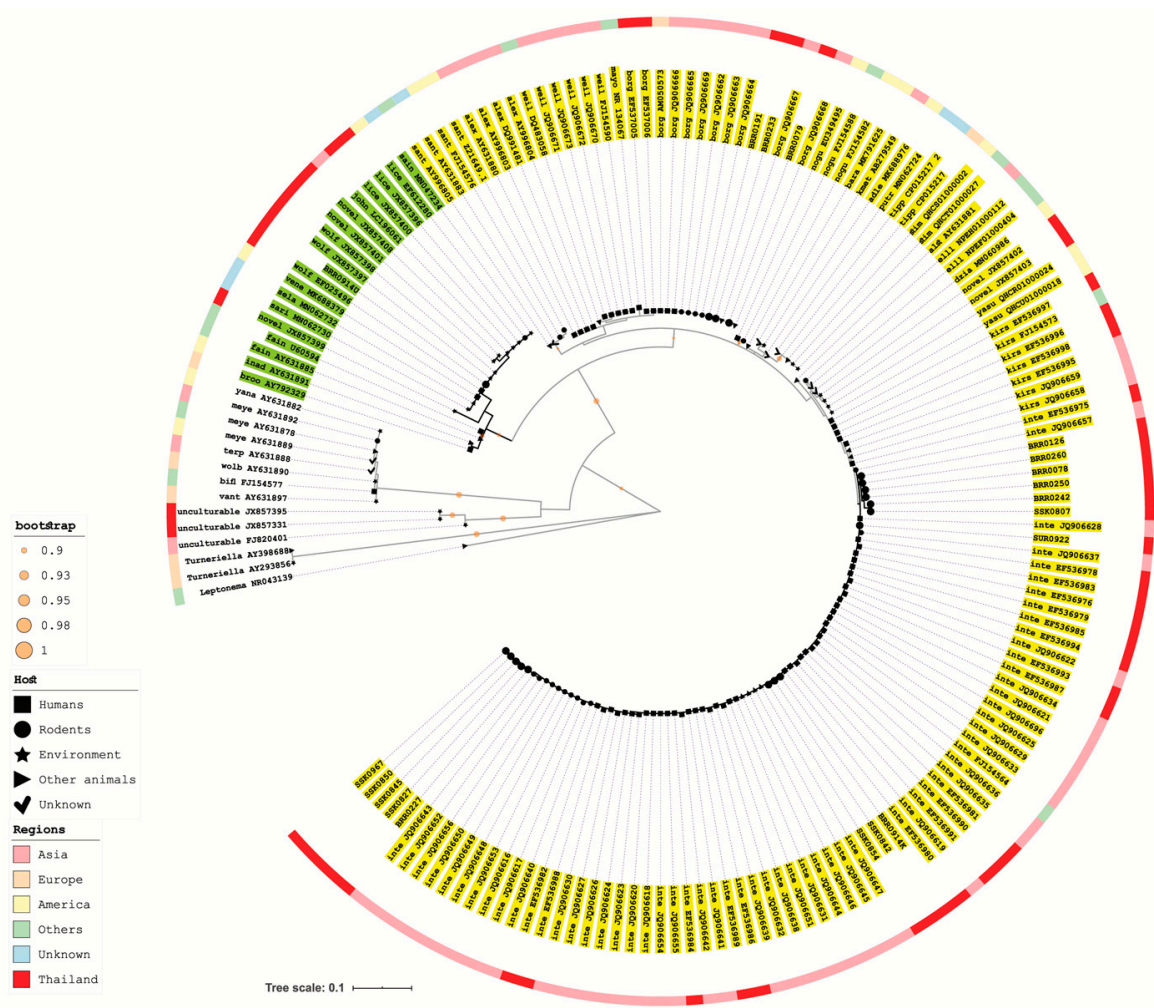

Figure 2. A phylogenetic tree of Leptospira species. A maximum likelihood tree was reconstructed from the $443 \mathrm{bp}$ of $16 \mathrm{~S}$ rDNA sequences using MEGA $X$ version 10.0.5., containing a total of 19 sequences from rodent samples (big black dots) together with 146 reference sequences from GenBank data; this included 36 official Leptospira species, unculturable Leptospira (clustering with the nonpathogen Leptospira species) and probable novel Leptospira species, which were used to reconstruct the tree as shown in Table S1. Three isolates from genus Leptonema and Turneriella were also included as out-groups. Different colors of the highlighted text represent three groups in the genus Leptospira; yellow for species in the pathogen group, green for species in the intermediate group, no highlight for the nonpathogens and out-group. Hosts of isolates are shown in different shapes: dots for rodents, squares for human, triangles for other animals, stars for environmental samples, and checkmarks for unknown hosts. The outer color strip demonstrates the geographical origins of isolates at the continent level (except for isolates from Thailand). Abbreviations are exemplified by the following: BRR, samples from Burirum; SUR, samples from Surin; SSK, samples from Sisaket; BRR0914K, the partial 16S rDNA sequences of the kidney sample from rodent no. 0914 trapped in Burirum; BRR0914U, the partial 16S rDNA sequences from the Leptospira isolated from a urine sample from rodent no. 0914 trapped in Burirum. GenBank accession numbers of the $16 \mathrm{~S}$ rDNA sequence are provided in Table S1. 
None of the kidney cultures from the 495-trapped rodents was positive for Leptospira. Urine samples were collected from 13 of these rodents and inoculated for Leptospira isolation. Culture was successful for 1/13 urine samples and the near full length of $16 \mathrm{~S}$ rRNA gene was used to determine the Leptospira species. The $16 \mathrm{~S}$ rDNA sequence of the LS0914U isolate (accession numbers KP120904 for $443 \mathrm{bp}$ of $16 \mathrm{~S}$ rRNA gene and KC662454 for 1304 bp of 16S rRNA gene) was identical to the sequence of a reference L. wolffii serovar Korat (GenBank no. EF025496.1) in the intermediate Leptospira group (Figure 2 and Supplementary Materials Figure S1).

\section{Discussion}

The objective of our study was to determine whether rodents with chronic Leptospira infection in highly leptospirosis endemic northeastern Thailand could be implicated as the source of human Leptospira infection. From 2011 to 2012, the MoPH reported annual leptospirosis incidence rates ranging from 16.8-30.9 per 100,000 in Burirum, Kalasin, Sisaket, and Surin provinces, which were higher than the overall average annual incidence of 6.6 per 100,000 for Thailand during the same period.

Three point six percent of rodents trapped in this study were positive for pathogenic Leptospira carriage. Most of the rodents, i.e., $87.5 \%$, trapped in this study were $R$. rattus and $R$. exulans. The rodent species trapped in this study are consistent with those reported in previous leptospirosis studies in Thailand $[7,12,21,22]$. These rodent species are commonly found in habitat types ranging from field to household, with each species showing distinct preferences for specific habitats within that range [23,24]. Rattus spp. were the most abundant species (15.0\%) and had a lower Leptospira prevalence (3.5\%) than other trapped species. These findings are consistent with the results from a study by Ivanova in Cambodia [24]. These more populous rodent species were trapped around households and in drier habitats which could be less suitable for Leptospira growth. The highest prevalence of Leptospira infection $(14.3 \%)$ was in rodents with the lowest density populations, i.e., B. indica $(0.7 \%)$, which suggests that this rodent species may play a relevant role in human Leptospira transmission in Thailand. In fact, during a leptospirosis outbreak in 2000, in the same region, a pathogenic clone of L. interrogans serovar Autumnalis ST34 was predominantly found in bandicoot rats and human cases [25]. Another survey of Leptospira infection in rodents in northern Thailand also reported high leptospirosis prevalence $(10.7 \%)$ in B. indica [21]. Moreover, habitat preference studies on B. indica have indicated that this species prefers agricultural fields [26,27], a prime environment for survival of Leptospira [28,29], and is rarely reported around or inside houses [26]. Leptospira prevalence in B. indica was highly variable between sites $(0-50 \%)$. However, the sample size was low for this species, given that our study was performed in villages, which is not the primary habitat for B. indica.

Despite the variety of rodent species captured, we detected only two Leptospira species, L. interrogans and L. borgpetersenii. A large proportion of rodent species were positive to L. interrogans (83\%; 15 of 18) (Figure S1). Assuming that this infection rate is representative of Leptospira infections in rodents, we would expect more environmental contamination with this Leptospira species compared to other species. Our observation of higher prevalence of L. interrogans than L. borgpetersenii in rodent population is consistent with previous work (unpublished data). The contribution of L. interrogans to human transmission in Thailand has been reported in previous studies, and was responsible for $96 \%$ of leptospirosis cases [25]. The ability of L. interrogans to survive longer in the environment compared to L. borgpetersenii may increase the likelihood of transmission from rodents to humans [30]. In our study, L. borgpetersenii was only identified in R. exulans. Rattus exulans were mainly captured around human residences. A study by Cosson et al. [21] on the effects of host species, sex, maturity, habitat, and locality on infection status found that the rodent locality, ecological habitat, and sex significantly influenced the likelihood of individual rodent infection. Moreover, their study also showed that the likelihood of Leptospira infection was not related to specific rodent species, but rather, to whether the habitat that the rodents were collected in was suitable for Leptospira survival. Leptospira borgpetersenii requires host to host transmission, and thus, can be transmitted in dry, peridomestic habitats [30], whereas $L$. interrogans requires humidity for survival [21]. This difference in survival requirements could explain 
why even though R. exulans can be infected with L. interrogans or L. borgpetersenii and the species is found peridomestically, the transmission of L. borgpetersenii between rodents and humans is less likely. Leptospira borgpetersenii requires direct contact for transmission, since it is unable to survive outside a host for prolonged periods. Therefore, transmission of L. borgpetersenii to humans is less likely, with only $3 \%$ of human leptospirosis infections being caused by L. borgpetersenii, as reported by Thaipadungpanit et al. [25], since direct contact between humans and rodents is rare. Transmission of L. interrogans to humans is more frequent, because this strain is able to survive in wet environments, and practices like barefoot rice farming bring humans into prolonged, close contact with such ideal, moist environments. Rodents are attracted to rice fields and, in their search for food, shed Leptospira in their urine as they move through the rice fields. Farmers spend hours immersed in water, often barefoot, while tending these rice fields, which increases the likelihood of infection by L. interrogans through any open wounds. These findings are in the same vein as those in a previous study reporting that L. interrogans and L. borgpetersenii required a difference in ecological niche to support their transmission [21].

In addition to detecting L. interrogans and L. borgpetersenii, we also isolated L. wolffii from one urine sample (Figure S1). The presence of L. wolffii in the urine culture could be explained by the ease of culturing this species compared to L. interrogans. The real time-PCR cycle threshold for sample BRR0914 ranged from 35-40, suggesting low number of Leptospira copies in the kidneys. The low load may be related to continuous host immune response, as suggested by Monahan et al. [31]. In the presence of a low-level coinfection, selective pressure in the urine culture media could favor the growth of L. wolffii over L. interrogans. The lipL32 gene is specific to pathogenic Leptospira. However, there is evidence for the possibility of co-infection with intermediate and nonpathogenic Leptospira, which are not detected using lipL32. Leptospira wolffii is a known environmental contaminant and potential pathogen [32-34] which has previously been detected in both animals and clinical human samples [35-38]. The presence of $L$. wolffii in culture was likely due to media competitive exclusion, but its importance in human disease is still inconclusive. Interestingly, an increasing number of human leptospirosis cases caused by the intermediate strains of Leptospira have been reported, such as L. wolffii in Thailand [38], India [36], Iran [35,37], and Ecuador [39], and Leptospira licerasiae in the Peruvian Amazon [40,41] and in a Japanese case returning from Brazil [42].

Human infection by pathogenic Leptospira can occur along several pathways. Often, activities associated with agricultural work, including cultivation and husbandry, are positively associated with exposure. Even something as common as living in a house with wooden walls can lead to an increased likelihood of infection due to a favorable environment for rodent infestation and residual, infectious nesting [43]. Although rodents were generally plentiful in our study sites, since leptospirosis is a zoonotic disease, the fact that other reservoirs, such as cattle and dogs, were found in the study sites led us to consider nonrodent sources of Leptospira transmission. According to a 1999 serosurvey of livestock by Thailand National Institute of Animal Health (NIAH), $69.2 \%$ of cattle tested in the northeastern provinces were positive for Leptospira [44]. A second NIAH serological investigation in 2001 found that $11.5 \%$ of livestock were seropositive for Leptospira across 36 Thai provinces. Of the locations surveyed, $30 \%$ of the infected animals were in the northeast region [45]. In addition, Wongpanit et al. [46] found a 63.6\% Leptospira seroprevalence in swamp buffalo in SakhonNakhon, a northeastern province. Farmers in the northeast commonly apply traditional rice farming methods involving the use of buffalo and cattle in paddy rice field preparation. These animals are often free to move between the household and the fields to graze when not being actively used by the farmer. Suwancharoen et al. [47] found that both water buffalo and domestic cattle throughout Thailand were shedding active Leptospira in their urine, highlighting another way these pathogens may circulate or be maintained in the environment. Even common domestic activities have a risk associated with this disease. In Nan province, Thailand, pathogenic L. interrogans were detected in asymptomatic humans, various household animals (cattle, dogs, and pigs) and a local underground water source often used for animal husbandry, i.e., for drinking or cleaning pens [48]. 
This study had several limitations: peridomestic sampling, potential sampling bias, and small numbers of non-Rattus species collected. We sampled rodents in villages near reported human leptospirosis cases. Traps were placed in areas of highest human activity, resulting in greater numbers of traps placed around housing rather than fields. As a result, our collections may be biased towards more rodents collected around houses than fields. Additionally, we collected small numbers of non-Rattus species, i.e., comprising $6 \%$ of the total rodents collected. The factors resulting in low collection rates of non-Rattus species vary by species, with the larger species B. indica and B. savilei being valued for human consumption; therefore, local practices of trapping and eating these species may have been the reason for the relatively lower numbers collected. Additionally, M. cervicolor and M. caroli prefer rice and corn fields, while S. murinus are found inside houses; as such, we may have collected relatively smaller numbers of these three species due to peridomestic sampling bias. Suncus murinus rodents are reported to inhabit multiple Southeast Asian countries and to prefer peridomestic habitats; however, two studies of rodent surveillance for leptospirosis in Thailand and Southeast Asia $[7,21]$ did not report collection of this rodent species. In contrast, a survey of Ivanova et al. of rodents in Cambodia reported high numbers of S. murinus ( $9 \%$ or 57/650), but noted that these were collected only in households. Therefore, either there are lower numbers of S. murinus in Thailand than Cambodia, or our peridomestic sampling methods may have biased us against collecting this species.

\section{Conclusions}

We detected pathogenic Leptospira in B. indica, R. exulans, and R. rattus, the reservoir hosts of Leptospira in northeastern Thailand. Two pathogenic Leptospira, L. borgpetersenii and L. interrogans, were detected in rodent populations. L. wolffii was found in the urine culture of $B$. indica, whose kidney samples were PCR-positive for L. interrogans and negative in culture. The proximity of reservoir habitats to sites of human activities may have facilitated transmission by exposure to an infected urine-contaminated environment. L. wolffii, recovered and isolated from rodent urine, could be a potential pathogen surviving in the environment and transmitting among rodents, the environment, and humans. The low evidence of Leptospira carriage in rodents from village areas with high incidence of human cases may indicate that other animals, especially domesticated animals, serve as potential reservoirs and play a role as transmission drivers of human leptospirosis. Additionally, the prevalence of carriage in B. indica in agricultural settings will be relevant to better understanding the contribution of this species to leptospirosis transmission.

Supplementary Materials: The following are available online at http://www.mdpi.com/2414-6366/5/4/154/s1, Table S1: GenBank accession numbers of the reference rrs gene and 19 of the 443-nucleotide $r r s$ of rodent samples from this study used for phylogenetic analysis. Supplementary Figure S1: A phylogenetic tree of Leptospira isolates originating from Thailand

Author Contributions: Conceptualization, P.K. and P.W.M.; methodology, P.K., J.T., S.L., T.M. and P.W.M.; validation, E.W.W., F.C., B.K.P.-S. and P.W.M.; investigation, P.K., J.T., S.L. and T.M.; formal analysis F.C. and P.K.; resources, E.W.W., A.L.S. and P.W.M.; supervision, E.W.W., A.L.S., F.C., B.K.P.-S. and P.W.M.; data curation, P.K., J.T., and S.L.; writing-original draft preparation, P.K. and P.W.M.; writing-review and editing, J.T., E.W.W., A.L.S., F.C., B.K.P.-S. and P.W.M. All authors have read and agreed to the published version of the manuscript.

Funding: This work was supported by the Armed Forces Health Surveillance Division, Global Emerging Infections Surveillance (GEIS) Branch, ProMIS ID ProMIS ID \# C0550_12_AF, Year 2012-2013.

Acknowledgments: We would like to thank the Bureau of Epidemiology, Department of Disease Control, Ministry of Public Health, Thailand for providing valuable epidemiological data. I would like to thank Ms Tippa Wongstitwilairoong and Ms Somporn Krasaesub for your outstanding contribution on the picture and statistical analysis in this work.

Conflicts of Interest: Material has been reviewed by the Walter Reed Army Institute of Research. There is no objection to its presentation and/or publication. The opinions or assertions contained herein are the private views of the author, and are not to be construed as official, or as reflecting true views of the Department of the Army or the Department of Defense. Research was conducted under an approved animal use protocol in an AAALACi accredited facility in compliance with the Animal Welfare Act and other federal statutes and regulations relating to animals and experiments involving animals and adheres to principles stated in the Guide for the Care and Use of Laboratory Animals, NRC Publication, 2011 edition. The authors declare no conflict of interest. 


\section{References}

1. Faine, S.; Adler, B.; Bolin, C.; Perolat, P. "Leptospira" and Leptospirosis; Medisci Press: Melbourne, Australia, 1999.

2. Levett, P.N. Leptospirosis. Clin. Microbiol. Rev. 2001, 14, 296-326. [CrossRef] [PubMed]

3. Turk, N.; Milas, Z.; Margaletic, J.; Staresina, V.; Slavica, A.; Riquelme-Sertour, N.; Bellenger, E.; Baranton, G.; Postic, D. Molecular characterization of Leptospira spp. strains isolated from small rodents in Croatia. Epidemiol. Infect. 2003, 130, 159-166. [CrossRef] [PubMed]

4. Bharti, A.R.; Nally, J.E.; Ricaldi, J.N.; Matthias, M.A.; Diaz, M.M.; Lovett, M.A.; Levett, P.N.; Gilman, R.H.; Willig, M.R.; Gotuzzo, E.; et al. Leptospirosis: A zoonotic disease of global importance. Lancet Infect. Dis. 2003, 3, 757-771. [CrossRef]

5. Ko, A.I.; Goarant, C.; Picardeau, M. Leptospira: The dawn of the molecular genetics era for an emerging zoonotic pathogen. Nat. Rev. Microbiol. 2009, 7, 736-747. [CrossRef] [PubMed]

6. Tangkanakul, W.; Smits, H.L.; Jatanasen, S.; Ashford, D.A. Leptospirosis: An emerging health problem in Thailand. Southeast Asian J. Trop. Med. Public Health 2005, 36, 281-288. [PubMed]

7. Wangroongsarb, P.; Petkanchanapong, W.; Yasaeng, S.; Imvithaya, A.; Naigowit, P. Survey of leptospirosis among rodents in epidemic areas of Thailand. J. Trop. Med. Parasitol. 2002, 25, 55-58.

8. Leelarasamee, A.; Chupaprawan, C.; Chenchittikul, M.; Udompanthurat, S. Etiologies of acute undifferentiated febrile illness in Thailand. J. Med. Assoc. Thai 2004, 87, 464-472.

9. Suttinont, C.; Losuwanaluk, K.; Niwatayakul, K.; Hoontrakul, S.; Intaranongpai, W.; Silpasakorn, S.; Suwancharoen, D.; Panlar, P.; Saisongkorh, W.; Rolain, J.M.; et al. Causes of acute, undifferentiated, febrile illness in rural Thailand: Results of a prospective observational study. Ann. Trop. Med. Parasitol. 2006, 100, 363-370. [CrossRef]

10. Sejvar, J.; Tangkanakul, W.; Ratanasang, P.; Dowell, S.F.; Sangjun, N.; Bragg, S.; Ashford, D.; Tappero, J. An outbreak of leptospirosis, Thailand-the importance of the laboratory. Southeast Asian J. Trop. Med. Public Health 2005, 36, 289-295.

11. National Disease Surveillance (Report 506). Thailand: Bureau of Epidemiology, Department of Disease Control, MoPH, Thailand. Available online: http://www.boe.moph.go.th/boedb/surdata/disease.php? dcontent=situation\&ds=43 (accessed on 8 February 2019).

12. Phulsuksombati, D.; Sangjun, N.; Khoprasert, Y.; Kingnate, D.; Tangkanakul, W. Leptospires in rodent, northeastern region 1999-2000. J. Health Sci. 2001, 10, 508-515.

13. Nelson, L.; Clark, F.W. Correction for sprung traps in catch/effort calculations of trapping results. J. Mammal. 1973, 54, 295-298. [CrossRef]

14. Lekagul, B.; McNeely, J.A. Mammals of Thailand; Association for the Conservation of Wildlife: Bangkok, Thailand, 1977.

15. McAvin, J.C.; Kengluecha, A.; Takhampunya, R.; Richardson, J.H. A field-expedient method for detection of leptospirosis causative agents in rodents. U.S. Army Med Dep. J. 2012, 22-28.

16. Boonsilp, S.; Thaipadungpanit, J.; Amornchai, P.; Wuthiekanun, V.; Chierakul, W.; Limmathurotsakul, D.; Day, N.P.; Peacock, S.J. Molecular detection and speciation of pathogenic Leptospira spp. in blood from patients with culture-negative leptospirosis. BMC Infect. Dis. 2011, 11, 338. [CrossRef] [PubMed]

17. Kumar, S.; Stecher, G.; Li, M.; Knyaz, C.; Tamura, K. MEGA X: Molecular evolutionary genetics analysis across computing platforms. Mol. Biol. Evol. 2018, 35, 1547-1549. [CrossRef] [PubMed]

18. Letunic, I.; Bork, P. Interactive Tree of Life (iTOL) v4: Recent updates and new developments. Nucleic Acids Res. 2019, 47, W256-W259. [CrossRef] [PubMed]

19. Weisburg, W.G.; Barns, S.M.; Pelletier, D.A.; Lane, D.J. 16 S ribosomal DNA amplification for phylogenetic study. J. Bacteriol. 1991, 173, 697-703. [CrossRef] [PubMed]

20. Matthias, M.A.; Díaz, M.M.; Campos, K.J.; Calderon, M.; Willig, M.R.; Pacheco, V.; Gotuzzo, E.; Gilman, R.H.; Vinetz, J.M. Diversity of bat-associated Leptospira in the Peruvian Amazon inferred by bayesian phylogenetic analysis of 16S ribosomal DNA sequences. Am. J. Trop. Med. Hyg. 2005, 73, 964-974. [CrossRef]

21. Cosson, J.F.; Picardeau, M.; Mielcarek, M.; Tatard, C.; Chaval, Y.; Suputtamongkol, Y.; Buchy, P.; Jittapalapong, S.; Herbreteau, V.; Morand, S. Epidemiology of Leptospira transmitted by rodents in Southeast Asia. PLoS Negl. Trop. Dis. 2014, 8, e2902. [CrossRef] 
22. Della Rossa, P.; Tantrakarnapa, K.; Sutdan, D.; Kasetsinsombat, K.; Cosson, J.F.; Supputamongkol, Y.; Chaisiri, K.; Tran, A.; Supputamongkol, S.; Binot, A.; et al. Environmental factors and public health policy associated with human and rodent infection by leptospirosis: A land cover-based study in Nan province, Thailand. Epidemiol. Infect. 2016, 144, 1550-1562. [CrossRef]

23. Herbreteau, V.; Bordes, F.; Jittapalapong, S.; Supputamongkol, Y.; Morand, S. Rodent-borne diseases in Thailand: Targeting rodent carriers and risky habitats. Infect. Ecol. Epidemiol. 2012, 2, 18637. [CrossRef]

24. Ivanova, S.; Herbreteau, V.; Blasdell, K.; Chaval, Y.; Buchy, P.; Guillard, B.; Morand, S. Leptospira and rodents in Cambodia: Environmental determinants of infection. Am. J. Trop. Med. Hyg. 2012, 86, 1032-1038. [CrossRef] [PubMed]

25. Thaipadungpanit, J.; Wuthiekanun, V.; Chierakul, W.; Smythe, L.D.; Petkanchanapong, W.; Limpaiboon, R.; Apiwatanaporn, A.; Slack, A.T.; Suputtamongkol, Y.; White, N.J.; et al. A dominant clone of Leptospira interrogans associated with an outbreak of human leptospirosis in Thailand. PLoS Negl. Trop. Dis. 2007, 1, e56. [CrossRef] [PubMed]

26. Herbreteau, V.; Gonzalez, J.P.; Andrianasolo, H.; Kittayapong, P.; Hugot, J.P. Mapping the potential distribution of Bandicota indica, vector of zoonoses in Thailand, by use of remote sensing and geographic information systems (a case of Nakhon Pathom province). Trop. Nat. Hist. 2005, 5, 61-67.

27. Thitipramote, N.; Suwanjarat, J.; Breed, W.G. Reproductive biology of the greater bandicoot rat Bandicota indica (Rodentia: Muridae) in the rice fields of southern Thailand. Curr. Zool. 2009, 55, 48-55. [CrossRef]

28. Lall, C.; Kumar, K.V.; Raj, R.V.; Vedhagiri, K.; Vijayachari, P. Prevalence and diversity of leptospires in different ecological niches of urban and rural areas of South Andaman Island. Microbes Environ. 2016, 31, 79-82. [CrossRef]

29. Muñoz-Zanzi, C.; Mason, M.R.; Encina, C.; Astroza, A.; Romero, A. Leptospira contamination in household and environmental water in rural communities in southern Chile. Int. J. Environ. Res. Public Health 2014, 11, 6666-6680. [CrossRef]

30. Bulach, D.M.; Zuerner, R.L.; Wilson, P.; Seemann, T.; McGrath, A.; Cullen, P.A.; Davis, J.; Johnson, M.; Kuczek, E.; Alt, D.P.; et al. Genome reduction in Leptospira borgpetersenii reflects limited transmission potential. Proc. Natl. Acad. Sci. USA 2006, 103, 14560-14565. [CrossRef]

31. Monahan, A.M.; Callanan, J.J.; Nally, J.E. Proteomic analysis of Leptospira interrogans shed in urine of chronically infected hosts. Infect. Immun. 2008, 76, 4952-4958. [CrossRef]

32. Thaipadungpanit, J.; Wuthiekanun, V.; Chantratita, N.; Yimsamran, S.; Amornchai, P.; Boonsilp, S.; Maneeboonyang, W.; Tharnpoophasiam, P.; Saiprom, N.; Mahakunkijcharoen, Y.; et al. Leptospira species in floodwater during the 2011 floods in the Bangkok Metropolitan Region, Thailand. Am. J. Trop. Med. Hyg. 2013, 89, 794-796. [CrossRef]

33. Chaiwattanarungruengpaisan, S.; Suwanpakdee, S.; Sangkachai, N.; Chamsai, T.; Taruyanon, K.; Thongdee, M. Potentially pathogenic Leptospira species isolated from a waterfall in Thailand. Jpn. J. Infect. Dis. 2018, 71, 65-67. [CrossRef]

34. Thongdee, M.; Chaiwattanarungruengpaisan, S.; Lekcharoen, P.; Yimchoho, N.; Buathong, R.; Wiriyarat, W. A Novel Genotype of Leptospira interrogans Recovered from Leptospirosis Outbreak Samples from Southern Thailand. Jpn. J. Infect. Dis. 2019, 72, 343-346. [CrossRef] [PubMed]

35. Zakeri, S.; Khorami, N.; Ganji, Z.F.; Sepahian, N.; Malmasi, A.A.; Gouya, M.M.; Djadid, N.D. Leptospira wolffii, a potential new pathogenic Leptospira species detected in human, sheep and dog. Infect. Genet. Evol. 2010, 10, 273-277. [CrossRef]

36. Balamurugan, V.; Gangadhar, N.L.; Mohandoss, N.; Thirumalesh, S.R.; Dhar, M.; Shome, R.; Krishnamoorthy, P.; Prabhudas, K.; Rahman, H. Characterization of leptospira isolates from animals and humans: Phylogenetic analysis identifies the prevalence of intermediate species in India. Springerplus 2013, 2, 362. [CrossRef] [PubMed]

37. Zakeri, S.; Sepahian, N.; Afsharpad, M.; Esfandiari, B.; Ziapour, P.; Djadid, N.D. Molecular epidemiology of leptospirosis in northern Iran by nested polymerase chain reaction/restriction fragment length polymorphism and sequencing methods. Am. J. Trop. Med. Hyg. 2010, 82, 899-903. [CrossRef] [PubMed]

38. Slack, A.T.; Kalambaheti, T.; Symonds, M.L.; Dohnt, M.F.; Galloway, R.L.; Steigerwalt, A.G.; Chaicumpa, W.; Bunyaraksyotin, G.; Craig, S.; Harrower, B.J.; et al. Leptospira wolffii sp. nov., isolated from a human with suspected leptospirosis in Thailand. Int. J. Syst. Evol. Microbiol. 2008, 58, 2305-2308. [CrossRef] 
39. Chiriboga, J.; Barragan, V.; Arroyo, G.; Sosa, A.; Birdsell, D.N.; España, K.; Mora, A.; Espín, E.; Mejía, M.E.; Morales, M.; et al. High prevalence of intermediate Leptospira spp. DNA in febrile humans from urban and rural Ecuador. Emerg. Infect. Dis. 2015, 21, 2141. [CrossRef]

40. Ganoza, C.A.; Matthias, M.A.; Collins-Richards, D.; Brouwer, K.C.; Cunningham, C.B.; Segura, E.R.; Gilman, R.H.; Gotuzzo, E.; Vinetz, J.M. Determining risk for severe leptospirosis by molecular analysis of environmental surface waters for pathogenic Leptospira. PLoS Med. 2006, 3, e308. [CrossRef]

41. Matthias, M.A.; Ricaldi, J.N.; Cespedes, M.; Diaz, M.M.; Galloway, R.L.; Saito, M.; Steigerwalt, A.G.; Patra, K.P.; Ore, C.V.; Gotuzzo, E.; et al. Human leptospirosis caused by a new, antigenically unique Leptospira associated with a Rattus species reservoir in the Peruvian Amazon. PLoS Negl. Trop. Dis. 2008, 2, e213. [CrossRef]

42. Tsuboi, M.; Koizumi, N.; Hayakawa, K.; Kanagawa, S.; Ohmagari, N.; Kato, Y. Imported Leptospira licerasiae infection in traveler returning to Japan from Brazil. Emerg. Infect. Dis. 2017, 23, 548. [CrossRef]

43. Suwannarong, K.; Chapman, R.S. Characteristics associated with contact with rodents in, around, and outside homes in Khon Kaen province, Thailand. Am. J. Trop. Med. Hyg. 2015, 92, 784-790. [CrossRef]

44. Suwancharoen, D.; Indrakamhang, P.; Neramitmansook, P.; Tangkanakul, W. Serological survey of Leptospiral antibodies in livestock in 5 northeastern provinces. J. Thai Vet. Med Assoc. 2000, 51, 9-18.

45. Suwancharoen, D.; Chaisakdanugull, Y.; Thanapongtharm, W.; Yoshida, S. Serological survey of leptospirosis in livestock in Thailand. Epidemiol. Infect. 2013, 141, 2269-2277. [CrossRef] [PubMed]

46. Wongpanit, K.; Suwanacharoen, D.; Srikram, A. Serological survey of leptospirosis in Thai swamp buffalo (Bubalus bubalis) in Sakon Nakhon province, Thailand. Agric. Nat. Resour. 2012, 46, 736-741.

47. Suwancharoen, D.; Limlertvatee, S.; Chetiyawan, P.; Tongpan, P.; Sangkaew, N.; Sawaddee, Y.; Inthakan, K.; Wiratsudakul, A. A nationwide survey of pathogenic leptospires in urine of cattle and buffaloes by Loop-mediated isothermal amplification (LAMP) method in Thailand, 2011-2013. J. Vet. Med Sci. 2016, 15-0493. [CrossRef] [PubMed]

48. Kurilung, A.; Chanchaithong, P.; Lugsomya, K.; Niyomtham, W.; Wuthiekanun, V.; Prapasarakul, N. Molecular detection and isolation of pathogenic Leptospira from asymptomatic humans, domestic animals and water sources in Nan province, a rural area of Thailand. Res. Vet. Sci. 2017, 115, 146-154. [CrossRef] [PubMed]

(C) 2020 by the authors. Licensee MDPI, Basel, Switzerland. This article is an open access article distributed under the terms and conditions of the Creative Commons Attribution (CC BY) license (http://creativecommons.org/licenses/by/4.0/). 